\title{
Conducting Market Research: An Aid to Organisational Decision Making
}

\author{
Remy Nyukorong
}

The Netherlands

doi: 10.19044/esj.2017.v13n10p1 URL:http://dx.doi.org/10.19044/esj.2017.v13n10p1

\begin{abstract}
As firms grow more and more in global markets, the role of reliable, verifiable, timely and high quality marketing research information to support decision-making becomes increasingly indispensable. The effectiveness and usefulness of decision-making is directly connected to the broad condition of the preferred sector(s) of the global market. To obtain complete information regarding the market entails designing and completing a significant number of activities arranged in logical sequence. Marketing research is the principal means by which firms comprehend existing and potential customers. Thus, this conceptual paper proposes a framework for accomplishing global market research ventures. In addition, the paper outlines a number of factors that should be taken into consideration by scholars who engage in global market research ventures. The factors represent the diversity of challenges that should be focussed on in conducting research globally. Specific attention is given to the nuances linked to data collection and analysis. Taking cognisance of the above, the informational core in the management of global firms should be assessed according to its value and role in world-wide marketing management. Lastly, technological advances should be integrated into the market research process in order to ease and accelerate research performed across national borders.
\end{abstract}

Keywords: Market information, organisational decision making, market research

\section{Introduction}

In today's global marketplace, the access to relevant information is the key competitive advantage in business operations. Also, the right understanding of relevant information calls for relevant competence among the workforce, whose ability in evaluating the current and making future projections based on global market conditions will result in managing the business in the most profitable and cost-effective way (Grubor, 2010). 
Therefore, market information is the key ingredient for creating an effective global marketing strategy as well as an important part of organizational decision-making process in operating both on the home and at international market level (Douglas \& Craig, 1983).

Marketing research is certainly one of the major means of collecting verifiable, timely, and trustworthy market information (Grubor, 2010). Collecting and making proper interpretation to such information demands practical skills and relevant expertise of engaged personnel, so that collected information can be passed on to decision-makers in the best possible way. A global marketing executive looks forward to reliable information allowing for the consideration of all the aspects of the subject-matter to be decided on. The appropriate and desired information may be based on knowledge, skills, experience and evaluation made by appropriate executives and professionals, but as well on market research carried out (Keegan and Green, 2013).

Developments in technology both expedite and simultaneously make more complex, the gathering of data on a world-wide basis. The growing and intensifying technological complexity of the communication infrastructure supports data gathering on a much wide-ranging and varied geographic coverage and with a speed hitherto unthinkable (Poynter, 2015; Mahajan, 2015; Ying Hon Ho, 2016). However, managers must become proficient at these tools and figure out their fundamental limitations as well as embedded biases.

The purpose of this paper is to delve into these changes in information requirements and propose the implications for doing marketing research within the global milieu. In particular, the paper scans the competences and skills international marketing researchers will require in order to carry out research in the increasingly diverse and fast changing world of commercial activity.

\section{Conducting market research in a new international market}

Information is one of the most essential elements of a winning marketing strategy. It is necessary that all marketers study a number of key topics to derive the benefits of contemporary information technology (Onkvisit and Shaw, 2004). In the first place, marketers need to comprehend the value of information technology as well as marketing information systems as strategic resources. Secondly, marketers need a structural model for information search and opportunity recognition. Thirdly, global marketers must have a broad understanding of the proper market research process. Lastly, marketers must be familiar with how to manage the marketing information gathering activity as well as the market research project (Keegan and Green, 2013). In this section, we discuss these issues in more detail. 


\section{Strategic value of information technology for global marketing}

Information technology (IT) relates to a company's processes in generating, storing, analyzing, exchanging, utilizing, and managing information (Carpano and Rahman, 1998; Keegan and Green, 2013). For instance, a management information system (MIS) offers managers and other key persons involved in the decision-making with a constant flow of information with regard to the operations of the company. An MIS must provide a methodology for collecting, examining, categorizing, storing, retrieving, and giving an account of significant data (Vyas, Vyas, \& Devra, 2014). The MIS should also encompass key features of an organization's external context, incorporating information about customers and competitors. Global competition increases the need for a useful MIS that is available and user-friendly, all through the organization (Keegan and Green, 2013; Onkvisit and Shaw, 2004).

In addition, an electronic data interchange (EDI) method enables a company's production units to submit orders, send out invoices, and carry out commercial activities electronically with other divisions of the company and outside companies (Carpano and Rahman, 1998; Keegan and Green, 2013). An important and valuable characteristic of EDI is its universality of operational designs. This enables computer systems at various companies to communicate with one another using the same language. Wal-Mart is wellknown for its highly developed EDI system.

Globalization has put a lot of demands on companies to realize as many economies as possible. Information technology offers numerous useful tools (Keegan and Green, 2013). As observed, EDI connects with dealers, allows retailers to enhance their inventory management system and replenish high-selling goods in a timely and efficient manner. Besides, retailers are more and more employing a practice called efficient consumer response (ECR) in an attempt to closely and familiarly work with dealers on inventory restocking (Carpano and Rahman, 1998). It is a cooperative project adopted by suppliers to work towards making better and enhancing the effectiveness of the supply chain aspect in order to benefit customers. Efficient consumer response system employs electronic point of sale information assembled by means of checkout scanners to aid vendors ascertain the pattern of product sales, the desires of customers and how the tastes of consumers change with geographical location.

Another innovative business model that aids companies gather, store, and study the information of regular consumers is known as customer relationship management (CRM). Injazz and Karen (2003) describe customer relationship management (CRM) as an amalgamation of technology, processes and people that strive to understand a company's customers. Thus, CRM is an idea or concept that gives importance to a two-way 
communication process involving company and customer. It is a cohesive approach to managing relationships by aiming at relationship development and customer retention. Firms that successfully apply the principles of CRM will reap the benefits of customer loyalty and long run profitability.

The customer relationship management technique enable organizations, for instance, Hewlett-Packard, Credit Suisse, and AT\&T to establish which customers are very important and to respond appropriately, in timely way, with tailor-made services and products that strongly correspond with customer needs and preferences. If rightly put into operation, CRM can ensure that workers are more dynamic and will boost company profitability. It will as well offer many gains to customers by supplying value-added services and goods (Keegan and Green, 2013).

The job of designing, systematizing, and putting into operation a good information system must be managed in a reasonable way that contributes to the general strategic orientation of the company. Contemporary information technology mechanisms give the resources for an organization's MIS and research activity to offer important information in an efficient, actionable and timely manner (Keegan and Green, 2013).

\section{Web-based research as the standard for market research}

Face-to-face and phone interviews were the elementary tools in the market researcher's quantitative toolbox for several years. However, around 2006, using a phone to conduct interviews in developed markets such as in Europe and the US had already started to weaken, and face-to-face interviews were now an asset of special worth employed aimed at events like intercepting pedestrians for a fast survey or poll. But in developing markets, face-to-face and phone were nonetheless the models of marketing research practice (Ying Hon Ho, 2016). A decade ago, the World Wide Web has further dislodged face-to-face and phone, as captured and depicted in the table below. They are in their single-digit percentages. 
Table 2, Based on ESOMAR industry reports.

\begin{tabular}{|c|c|c|}
\hline Global Market Research Methodologies & 2006 & $\begin{array}{c}2014 \\
\text { (latest available } \\
\text { statistics) }\end{array}$ \\
\hline Total quantitative & $83 \%$ & 73\% \\
\hline Online & $16 \%$ & $23 \%$ \\
\hline Automated digital/electronic & - & $21 \%$ \\
\hline Phone & $19 \%$ & $9 \%$ \\
\hline Face-to-face & $12 \%$ & $8 \%$ \\
\hline Mobile/Smartphone & - & $3 \%$ \\
\hline Postal & $4 \%$ & $2 \%$ \\
\hline Online traffic/audience & - & $2 \%$ \\
\hline $\begin{array}{c}\text { Other quantitative (e.g. syndicated } \\
\text { services) }\end{array}$ & $32 \%$ & $5 \%$ \\
\hline Total qualitative & $14 \%$ & $16 \%$ \\
\hline Other & $3 \%$ & $11 \%$ \\
\hline
\end{tabular}

Source: Adapted from Ying Hon Ho (2016)

Researchers' conducting business-to-business (B2B) quantitative research in modern times, now employ web panels and web surveys as the standard across the business world. Also, consumer researchers use the web as the standard for research projects in mature markets. Web is also gaining feasibility, accessibility, efficacy and economy in emerging markets.

\section{Market research and other technological innovations}

The founding and coming into the market of Apple's iPhone in 2007 began a mobile revolution. The development and ascent of the smartphone since that time has enhanced the research toolkit with an innovative mobile strategy, which is displaying at 3 percent as of the 2014 statistics as captured in the table above. However, it is important to note that there are other 
technology-based research approaches on the list that were not existing, far back in 2006.

Several ground-breaking market research technologies have been initiated in the last 10 years. For example, eye-tracking is today a familiar approach in the methodology listing of some firms. With this technology, consumers' eyeballs are tracked beyond probing verbally what they purchase or look at. Life Slicer ${ }^{\mathrm{TM}}$, which is a tiny camera worn by a consumer that makes photographs or pictures every few minutes to portray "a day in the life," has become one of the brand new technologies that is currently used for ethnography (Ying Hon Ho, 2016). There are other innovations such as the fMRI, also known as facial expression coding, which modern marketing researchers are eager to explore. In brief, research methods have changed dramatically to technology-based solutions in the last 10 years.

\section{Social media technology}

Social media, on the whole, has become an important dimension of the consumer lifestyle all over the world. According to Ying Hon Ho (2016), social media has three basic uses in market research:

Social media as method: A number of research firms now use social media as an important platform to interact with customers and consumers. For example, a researcher could link up with a chat room for sports car enthusiasts to run an online ethnographic enquiry within the target community.

Social media as data: People now review social media content produced by users on both Twitter and Facebook, to name just a few.

Social media as both method and data: There are now in existence market research online communities (MROCs), which are usually defined as "online focus groups on steroids". These are closed and exclusive communities that normally engage well-focused target respondents enrolled for a participation of around 1-3 months.

Market research has witnessed massive efficiencies. A great number of these developments have contributed to one outcome: the market scientist has now become more efficient in gathering and combining data from various sources than in any period in the past.

\section{Sources of Market Information}

Even though scanning is a very important source of information, academic research has revealed that headquarters top management of global firms get as much as two-thirds of the information they require from personal sources (Keegan and Green, 2013). This means that a large amount of external information is derived directly from executives based overseas markets in company subsidiaries. These top managers are more likely to 
have created a communication network with distributors, suppliers, clients, consumers, as well as representatives of government.

Other sources of information come from friends, social contacts, professional colleagues, experts, and potential new workforce (Daneshjo and Kravec, 2014). Also, direct sensory perception gives an important context for data obtained through human and textual sources. Direct perception engages all the senses. This entails seeing, hearing, feeling, tasting or even smelling for oneself to determine the things that are going on within the a particular environment (Keegan and Green, 2013). Over and over again, the contextual information or perspective one obtains from observing a particular situation can also be of assistance to fill in the big picture. Marketing scholars should use multiple sources of secondary data (FAO, 2017). These diverse sources can be validated as confirmation of one another.

\section{Steps to conducting a formal market research}

Market research is a project-specific, methodical gathering of relevant data. It is an activity that connects the customer, consumer and society to the marketer through information (Young and Javalgi, 2007). Thus, global market research relates customers, consumers and marketers through information collected on a world-wide scale (American Marketing Association, 1995). The major challenge of international marketing research is to identify and act in response to variations found among different countries that affect the way information is acquired (Keegan and Green, 2013). These differences may include historical, political, religious, cultural, linguistic, market and economic.

Market research can be carried out in two different ways. The first is using in-house staff to design and implement the market research. The second is to outsource an outside research firm that is has expertise in market research. In global marketing, Keegan and Green (2013) recommend that a combination of internal (in-house) and outside research efforts should be used.

The process of gathering data and translating it into valuable information can be rather painstaking and meticulous. In the discussion that follows, this paper focuses on eight fundamental steps of conducting a formal market research: information requirement, problem definition, selection of unit of analysis, examination of data availability, assessment of the value of research, data analysis, interpretation and presentation of the data (Keegan and Green, 2013).

1. Information need: As the saying goes, "a problem well defined is a problem half solved". Hence, regardless of the particular situation that triggers the research effort in motion, the two foremost questions which a global marketer must be concerned about are: (1) what relevant information 
is needed, and (2) why is the information needed? Table 1 below shows a list of several subject groupings that may necessitate research. The groundwork for an international marketing information system is a set of themes pertaining to the desired information that is considered necessary. The broad framework recommended by Keegan and Green (2013), which is illustrated in Table 1 below is made up of six broad information categories.

Table 1-1 Information Categories for International marketing Information System

\begin{tabular}{|c|c|c|}
\hline & Broad Category & Variables Covered \\
\hline 1 & Market potential & $\begin{array}{l}\text { Demand estimates, consumer behaviour, review of } \\
\text { products, channels, communication media }\end{array}$ \\
\hline 2 & Competitor information & $\begin{array}{c}\text { Corporate, business, and functional strategies. Resources } \\
\text { and intentions, capabilities }\end{array}$ \\
\hline 3 & Foreign exchange & $\begin{array}{c}\text { Balance of payments, interest rates, attractiveness of } \\
\text { country currency, expectations of analysts }\end{array}$ \\
\hline 4 & Prescriptive information & $\begin{array}{l}\text { Laws, regulations, rulings concerning taxes, earnings, } \\
\text { dividends in both host and home countries }\end{array}$ \\
\hline 5 & Resource information & $\begin{array}{c}\text { Availability of human, financial, physical, and } \\
\text { information resources }\end{array}$ \\
\hline 6 & General conditions & $\begin{array}{l}\text { Overall review of socio-cultural, political, technological } \\
\text { environments. }\end{array}$ \\
\hline
\end{tabular}

Source: Keegan \& Green, 2013

Research is frequently embarked on after a specific problem or opportunity has offered itself. For instance, it could be that a competitor is making inroads in one or more key markets within the business world somewhere. It could also be that research on local taste is needed to decide whether or not a food product must be custom-made.

Once the subject matter has been established, the next stage is the actual gathering and assembling of relevant information. The structure outlined above meets two important conditions. First, the framework encompasses all the subject matter necessary for a company that operates globally. Secondly, the various thematic areas in the framework are independent of one another (mutual exclusivity). Therefore, any type of information covered by the model can be appropriately put into one and only one broad category. This may be achieved by means of either surveillance or search. The surveillance approach enables the marketer to involve herself in informal information gathering. Marketers with global orientation are incessantly alert and keeping their eyes open for information concerning possible opportunities and threats localised in different parts of the business environment.

2. Identifying and defining the problem: At this step, the problem will have been identified through internal and external secondary sources including sales revenues, customers demographics, purchase patterns, industry reports, newsletters, magazines, trade associations, corporate 
executive interviews and other related sources (Research Lifeline, 2012). Also, internal discussions would have been held, at least by management, and further definition of the issue required (Gibson, 2012). This is to make sure that the firm is working on the real problem.

For instance, Keegan and Green (2013) reported that when Mattel launched Barbie in the Japanese market; executive managers thought that girls in Japan would experience the doll's design really as attractive and charming as the girls in the United States felt or experienced. On the contrary, the Japanese girls did not. Similarly, when the Disney Company started Disneyland Paris, the employees of recreational centres were expected to succumb to a careful set of laws concerning wears, costume jewellery, and other expressions of special individual appearance. The reason was to obtain assurance that guests procure the kind of experience associated with the Disney celebrity (Keegan and Green, 2013).

The above goes to illustrate the fact that when an individual's homecountry beliefs and values influence the judgement of a foreign culture or nation, the self-reference criterion (SRC) sets in. As these above examples have revealed, conjectures that firms make based on home-country practice can end up to be inaccurate. Consequently, when entering or getting engaged in global markets, it is paramount to have eyes wide open. Global marketers in particular must be sensitive to the effect that self-reference criterion can have on their business activities (Lee, 1966). The realisation and appreciation of SRC improves management's enthusiasm to carry out more research, make sure that research design has minimum 'how-country' preconception and encourages management's openness to research findings (Keegan and Green, 2013).

3. Choose a unit of analysis: This third step requires the marketer to work out in which location (s) of the world the company will engage itself in doing business and seeking, as much as possible, concerning the firm context in the location(s) earmarked. In this case, the unit of investigation could be either a specific country or it could also be an entire region (Cooper, 1996). In certain occasion, the marketer is only attracted to a sector that is global in nature.

4. Examine data availability: Handling an already existing data saves resources in terms of money and time. An economical methodology to market research and information assembling starts with desk research. Personal files, corporate or public libraries, internet or web-based catalogues, government survey records, and trade unions are some of the data sources which can readily be accessed with less effort and cost (Keegan and Green, 2013). When information is composed from a variety of sources, the danger is that some of these data sources may lack credibility and therefore cannot be trusted for decision-making purposes. Where information is credible and 
trustworthy, there may still be a few discrepancies and irregularities from one source to another. Therefore, care must be observed.

5. Measure value of research: Any scientific research entails investment of financial resources and quality time from the side of management. This should be taken into consideration and a mandatory costbenefit analysis should be worked out before going further with the research project. However, there may be isolated cases where a company may still have to go ahead with the same option regardless of what the research will indicate. In situations where additional data is required to guarantee a high quality decision, a reasonable assessment of an official research project may show that the cost involved in executing the research is clearly too much. For that reason, the market researchers need to work out ways that will keep expenses and costs at the level of the market's returns possibility (Keegan and Green, 2013). It is advisable also to stick to easy on the pocket research projects that really give up some classiness or statistical meticulousness to accomplish results within the limits of the available research funds.

6. Design the research: It is strongly recommended by marketing scholars to employ multiple indicators instead of a single measure (David, 2004; Keegan \& Green, 2013).This means utilizing the triangulation technique in the data gathering process. Every global organization need to work out tailored-made measures exclusive to the given industry, product/service market, or business model, which have in the past shown to be effective in forecasting potential (David, 2004). Markets should never be evaluated individually. It is much better to usually perform comparative assessments in various markets. This makes it possible for managers to use selection approach whereby different rankings and situations can be considered. Furthermore, it is critical to encourage observation of human actions such as purchasing patterns and other actions should be ascribed more weight than written reports or people's views concerning buying plans. Survey research, interviews, consumer panels, observation, and focus groups are effective primary data gathering tools (Keegan and Green, 2013; Redlick-Amiray and Higginbottom, 2014), which the marketer can employ to collect relevant business information.

The Internet has also become one of the most valuable and practical technologies of the present age. It assists people not only in their personal but also professional lives. The latest Internet domains which have increased in popularity are the social media networks sites like Myspace, Twitter, Facebook, Instagram, WhatsApp and the social media devices (SMD) such as Tablets, iPads, and Smartphones which facilitate being up-to-date and well-informed (Redlick-Amiray and Higginbottom, 2014). Behaviour at these sites can be monitored and exposing interest pertaining to services and 
products information including reactions to promotional offers and deals (Craig \& Douglas, 1999).

Video recording of buyers or consumption settings can give a rich source of information concerning the role of environmental and circumstantial factors on customer behaviour and response patterns in diverse settings and cultures. Video recording of buyers in an in-store situation offers a lot of information concerning visual indications and how this impact on product evaluation that cannot easily be gained from other forms of data gathering (Restall and Anton, 1995). In developing markets, video recording of customer practice and consumption behaviour usually gives in-depth understanding of how buyers use services (products) as well as how these are entrenched in the cultural frame of society, and the experiences and connections of foreign goods and brands.

7. Analyze the data: The raw data put together must be carefully and rigorously put to various analyses to meet the needs of decision makers. Thus the first important thing to do is to prepare or clean up the raw data before further analysis is continued (Keegan and Green, 2013). Data processing carried on by organizing the data in tabular form with the aid of appropriate statistical methods such as ANOVA, regression, factor analysis, cluster analysis, perpetual mapping, conjoint analysis, and so on.

8. Present the findings: The written report which is compiled from the market research must be practical and worthwhile to managers as input to the decision-making process. Therefore, the report must have a connection to the research problem outlined in the first step. Normally, it is prudent and desirable that the key and most important research findings to be reviewed succinctly in the form of a memorandum or what is termed executive summary. The key findings along with the principal report should now provide the basis for managerial action (Keegan and Green, 2013).

The process of gathering relevant market data and adapting it into useful information can be a bit detailed, as depicted in figure 1, below. 


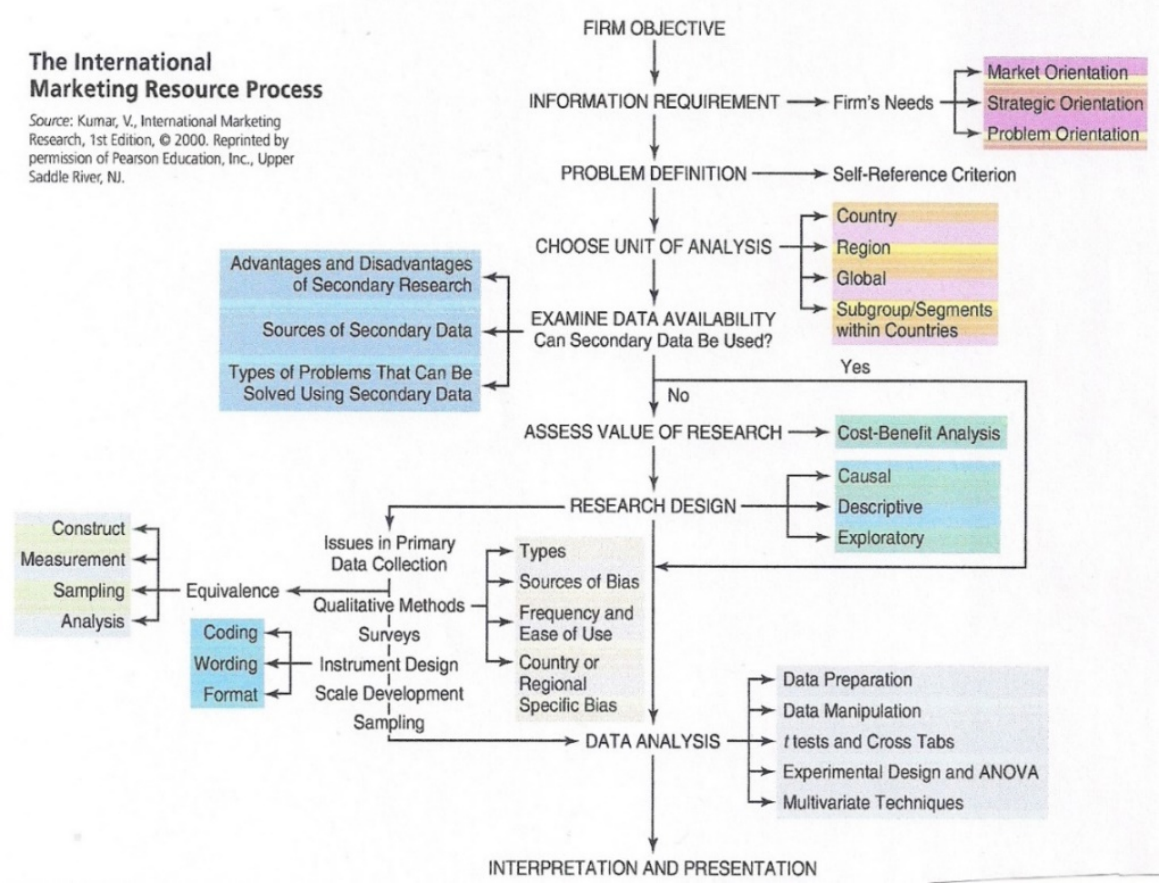

Figure 1. Steps in conducting international marketing research

\section{Managing the information collection system}

The decisive issue has to do with how much control headquarters will have over research as well as the overall administration of the information system of the company. To facilitate comparability of the relevant information, the research must make use of both emic and etic approaches (Keegan and Green, 2013). Synchronizing and coordinating the company's business activities is necessary to keep the surveillance of the various issues of the business milieu regarding which the company desires to continue to be updated on.

The purpose of this pursuit which can be described as organizational intelligence is aimed at standardizing and regulating the gathering and examination of competitive intelligence to provide for the various needs of the company as a whole (Gilad, 1989). This is because competitive intelligence concentrates on the direct corporate situation such as suppliers, clients, competitors and other forces with whom the company transacts business with (Shin, 2013). The major task of systematized competitive intelligence in forming strategy will rest on its capacity to add-on, rather than substitute, the casual activities of the workforce, particularly senior executives.

The advantages of organized intelligence are discovery of new business prospects, exchange of ideas, increased aptitude to expect surprises, enhancing top managers critical and rational skills, and finally, incorporating 
different ideas (Craig and Douglas, 2001; Keegan and Green, 2013). Thus, when there is coordination in an organization, competitive intelligence grows to be a critical strategic resource which can then be set out as a competitive advantage for the company. In the same vein, the absence of top management coordination makes the gains of organized intelligence only stay put at personal and localized level (Gilad, 1989; Shin, 2013).

The literature has also explained four stages in decision making: intelligence, design, choice and implementation (FAO, 2017). This means that problems have to be identified and understood; once identified solutions must be proposed; once solutions are proposed, choices need to be made concerning a specific solution; and lastly, the solution has to be put into practice. Consequently, it can be observed that designers of the information system have to consider the needs of marketing managers at every stage of the decision making process, as each stage has its own prerequisites and constraints.

\section{Implications for global marketing research}

Intense changes in the international marketing environment in addition to technological developments in data gathering, analysis and distribution suggest that marketing scholars may be required to broaden their skills and competences in order to plan, execute and interpret research in the current century. As research endeavours are organised to fit markets where there is the greatest potential, marketing scientists will have to cultivate the competences and skills to design and do research in these settings (Barnard, 1997). New research tools involving the most modern technology will have to be learned and creative methodologies to understanding human behaviour in various cultural circumstances established (Craig and Douglas, 2001). The skill to figure out and incorporate multifaceted data from different sources and geographical settings will also be crucial in order to offer insightful suggestions for the firm's global marketing strategy.

In answer to an open-ended survey question on how the knowledge, skills and capabilities required by personnel in the marketing research department, respondents mentioned a constant need for professional and experienced staff (Ashcraft, 1991). Accordingly, these research executives make compelling demands on the employees under them due to the closer working relationship with personnel of other departments within the firm. Staff of the marketing research department need to demonstrate general business knowledge and a better insight of other departments, generate action-oriented performance outcomes, and be technically intelligent as new technology is being developed. Other skills and capabilities needed by marketing researchers are deeper knowledge in business issues, knowledgeable in sales and product development, possess computer and 
statistics skills, analytical to simplify facts, creativity and team player (Ashcraft, 1991).

Carrying out market research in a global market setting needs a lot of skills and new learning. This involves a more thorough understanding of local culture (Young and Javalgi, 2007). Cultural factors such as language, religion, education, time orientation, aesthetics, gender roles and social institutions are closely linked to national culture (Javalgi and White, 2002), and have a huge impact on the suitability and adoption of new services and products. The influence of culture is multidimensional and complex in the sense that cultural standards that are significant to one group of people could have little meaning to another. Cultural variations profoundly affect adoption of services and products as well as other kinds of market behaviour. Undoubtedly, cultural influences have assumed strategic significance that cannot be overlooked when marketing existing and/ or new services and products (Onkvisit and Shaw, 2004). Social elements represent a culture's basic arrangement, including its various institutions and groups, its edifice of social organisation, and the process by which both operant and operand resources are allocated. Certainly, social arrangement affects market research decisions such as the cost of undertaking the research, getting to the target markets, gathering the data, and so on.

In-house market research executives who are conscious and attentive to the unique context of global market research will be more capable of designing and implementing strategies that contribute significantly to their company's competitive advantage in the marketplace. Furthermore, paying great attention to the challenges outlined and discussed in this paper will produce market research findings that are more impactful and more frequently put to use by clients.

\section{Conclusion}

To conduct business an international market, even a well-known one, without carrying out market research escalates the risk of misunderstanding and underestimating the economic opportunity.

Emerging markets or transition economies are obviously the most quickly growing destination for international market research. Emerging markets also demand more in-depth, more regular and more holistic research considering the fact they are immature and yet with fast growth of many service and product types, which appeals to market entry players. The difficulties linked with market research in developing markets are by no means impressive. The way to surmounting these problems arises by not uncritically introducing research models that have met with success in another place, particularly in the developed world. This then entails the implementation of fact-based approaches to: (a) utilising tailored market 
environment research to create standard information in relation to the business eco-system to bring up to date the design of effective surveys and methodologies, instead of depending on published data often non-existent, (b) utilising local forms of influence to overcome uncertainties concerning research, (c) dependent more on face-to-face interviewing and probing, supported by telephone or internet research where appropriate, (d) ensuring both cultural and linguistic competence of interviewers, at the same time allowing ample time and resources to traverse a more perplexing physical setting, and finally (e) evaluating responses in a socially and creatively grounded way, while making allowances for ethnographic research to address the constraints of self-reporting.

Technological innovations, such as the internet (Twitter, Facebook, Instagram, LinkedIn, MySpace, etc.), should be integrated in the research process so as to expedite and facilitate research carried out across the world (Curran, Graham \& Temple, 2011; Mahajan, 2015; Mangold and Faulds, 2009) The application of several internet tools such as online surveys, search engines, and emails, global firms can gather a broad range of data and information concerning foreign markets. The internet is very promising source of information because it is fast and economical. It is the communications technologies and innovation of information that has given the prospect for information accessibility that is significantly more costeffective for companies everywhere in the world.

Future research is required to understand how companies can draw on social media analytics to carry out predictive analysis on consumer behaviour.

\section{References:}

1. Ashcraft, L. (1991). The involving marketing research industry. AmericanMarketing Research, 23-29. Retrieved 26 march 2017, from https://archive.ama.org/archive/ResourceLibrary/MarketingResearch/ documents/7465050.pdf

2. Barnard, P. (1997). Global developments and future directions in marketing research, Globalization and the Millennium: Opportunities and Imperatives, Marketing Science Institute, Brussels, 16-17 June, cited in Craig, C. S., and Douglas, S. P. (2001). "Conducting international marketing research in the twenty-first century”, International Marketing Review, 18, 1, pp. 80-90.

3. Bennett, P.D., ed., (1995). Dictionary of marketing terms ( $2^{\text {nd }}$. Ed.). Chicago: American Marketing Association, p.169.

4. Carpano, C., \& Rahman, M. (1998). Information technology, international marketing and foreign subsidiaries market share. Multinational Business Review, 6(1), 36-49. 
5. Craig, C. S., \& Douglas, S. P. (2001). Conducting international marketing research in the twenty-first century, International Marketing Review, 18(1), 80-90.

6. Cooper, P. (1996). Internationalization of qualitative research, ESOMAR Congress, Monte Carlo.

7. Curran, K., Graham, S., \& Temple, C. (2011). Advertising on Facebook. International Journal of E-Business Development, 1, 2633.

8. Daneshjo, N., \& Kravec, M. (2014). Sources of information for data ware of strategic marketing. International Journal of Interdisciplinarity in Theory and Practice, 5, 22-24.

9. David, A. (2004). The mirage of global markets. Upper Saddle River, NY: Financial Times Prentice Hall.

10. Douglas, S.P., \& Craig, C.S. (1983). Examining the performance of US multinationals in foreign markets. Journal of International Business Studies, 12, 51-62.

11. Food and Agriculture Organization (2017). Marketing research and information system: Secondary sources of information (Chapter 9). Retrieved $26 \quad$ March 2017, from http://www.fao.org/docrep/w3241e/w3241e03.htm

12. Gibson, D.L. (1998). Defining marketing problems. Don’t spin your wheel solving the wrong puzzle. Market Research, Spring Issue, 512. Retrieved 26 March 2017, from http://www.mktgsensei.com/AMAE/Marketing\%20Research/proble m_definition_Gibson_MR_1998.pdf

13. Gilad, B. (1989). The role of organized competitive intelligence in corporate strategy. Columbia Journal of World Business, 24, 29-35. Retrieved 26 March 2017, from EBSCO database.

14. Grubor, A. (2010). Information global marketing management. Management Information Systems, 5(2), 3-7.

15. Injazz, J.C., \& Karen, P. (2003). Understanding customer relationship management (CRM): People, process and technology. Business Process Management Journal, 9 (5), 672688. Doi: 10.1108/14637150310496758.

16. Javalgi, R., \& White, D.S. (2002). Strategic challenges for the marketing of services internationally. International Marketing Review, 19 (6), 563-581.

17. Keegan, W.J., \& Green, M.C. (2013). Global marketing, $7^{\text {th }}$ edn. Upper saddle River, NJ: Prentice Hall.

18. Lee, J. A. (1966, April). Cultural analysis in overseas operations. Harvard Business Review,106-114. 
19. Mahajan, R. (2015). Use of social media as a new investigative tool in marketing research for small business. International Journal of eEducation, e-Business, e-Management and e-Learning, 5(3), 129135.

20. Mangold, G.W., \& Faulds, D.J. (2009). Social Media: The New Hybrid Element of the Promotion Mix. Business Horizons, 52, 357365.

21. Onkvisit, S., \& Shaw, J. (2004). International marketing: Analysis and strategy ( $4^{\text {th }}$ ed.). New York, NY: Routledge.

22. Poynter, R. (2015). The utilisation of mobile technology and approaches in commercial market research. In: Toninelli, D, Pinter, R \& de Pedraza, P (eds) Mobile Research Methods: Opportunities and Challenges of Mobile Research Methodologies, pp.11-20. London: Ubiquity Press. DOI: http://dx.doi.org/10.5334/bar.b.License:CC-BY 4.0.

23. Redlich-Amirav, D., \& Higginbottom, G. (2014). New emerging technologies in qualitative research. The Qualitative Report, 19 (26), 1-14. $\quad 26$ Metrieved March 2017, from http://nsuworks.nova.edu/tqr/vol19/iss26/3

24. Restall, C., \& Auton, R. (1995).The future of qualitative research from passivity to interaction, unpublished document. The Research Business Group, London.

25. Research LifeLine (2012). The six steps in conducting quantitative marketing research. Survey Process White Paper Series, Polaris Marketing Research, Inc. Retrieved 26 March 2017, from http://cdn2.hubspot.net/hub/58820/docs/rl_process_wp_six_steps_qu ant_mr.pdf

26. Shin, S. (2013). The influences of market information management and marketing control in small-sized firms in Korea. International Business Research, 6 (11), 51-66.

27. Vyas, V., Vyas, S., \& Devra, N. (2014). Applications of management information system in marketing management. International Journal of Information \& Computation Technology, 4, (17), 1825-1829.

28. Ying Hon Ho, D. (2016, July). How market research has evolved over the past decade. Retrieved 27 March 2017, from https://www.marketstrategies.com/blog/2016/07/how-marketresearch-has-evolved-over-the-past-decade/

29. Young, R.B., \& Javalgi, R.G. (2007). International marketing research: A global project management perspective. Business Horisons, 50, 113-122. 